\title{
Custos econômicos da diminuição dos serviços ecossistêmicos nas unidades de conservação da Amazônia
}

A valoração econômica de bens e serviços ambientais é fruto de um entendimento integrado em que se apresenta em uma interface que envolve o sistema natura e o econômico e com isso sua utilização tem se ampliado em todo o mundo. A percepção de que o ecossistema equilibrado fornece benefícios para a sociedade é um pressuposto básico desta atividade. Nesta perspectiva, o artigo em questão se propõe a apreender os custos econômicos provenientes da diminuição de capacidade da floresta amazônica em oferecer os serviços ecossistêmicos necessários para manutenção da vida no planeta, causadas pelo processo de desflorestamento no ano de 2018. O estudo destes custos é realizado nas unidades de conservação na Amazônia brasileira. Para os procedimentos de valoração de bens e serviços ambientais foi utilizado a metodologia de transferência de benefícios. O resultado encontrado foi de $\mathrm{R} \$ 582.137 .181,06$. Dentre esta cifra, a maior perda foi nas Reservas Biológicas, refletindo quase 50 \% do total. O estudo mostrou a importância da atividade de valoração nos processos que envolvem decisões políticas e econômicas. Pois, poderá promover uma melhor decisão por parte tanto dos gestores públicos, que precisam alocar os recursos públicos para atender o máximo bem-estar para a população, quanto como para os agentes privados.

\section{Economic costs of decreasing ecosystem services in Amazonian conservation units}

\begin{abstract}
The economic valuation of environmental goods and services is the result of an integrated understanding in which it presents itself in an interface that involves the natural and the economic system and with this, its use has been expanded around the world. The perception that the balanced ecosystem provides benefits to society is a basic assumption of this activity. In this perspective, the article in question proposes to apprehend the economic costs arising from the decrease in the capacity of the Amazon forest to offer the ecosystem services necessary for the maintenance of life on the planet, caused by the deforestation process in 2018. The study of these costs is carried out in the conservation units in the Brazilian Amazon. For the procedures of valuation of environmental goods and services, the methodology of benefit transfer was used. The result found was $\mathrm{R} \$ 582,137,181.06$. Among this figure, the biggest loss was in the Biological Reserves, reflecting almost $50 \%$ of the total. The study showed the importance of the valuation activity in the processes that involve political and economic decisions. It can promote a better decision by both public managers, who need to allocate public resources to meet the maximum welfare for the population, as well as private agents.
\end{abstract}

Keywords: Environmental services; Tropical forest; Economic-ecological valuation.

Topic: Valoração e Economia Ambiental

Reviewed anonymously in the process of blind peer.
Received: 03/02/2021

Approved: 26/02/2021
Augusto César Trigueiro Félix (iD)

Universidade Federal de Campina Grande, Brasil

http://lattes.cnpq.br/6414132347837894

http://orcid.org/0000-0001-8223-780X

augusto cesar 3@hotmail.com

Isabel Lausanne Fontgalland

Universidade Federal de Campina Grande, Brasil

http://lattes.cnpq.br/3447455428798868

http://orcid.org/0000-0002-0087-2840

isabelfontgalland@gmail.com
Referencing this:

FÉLIX, A. C. T.; FONTGALLAND, I. L.. Custos econômicos da diminuição dos serviços ecossistêmicos nas unidades de conservação da Amazônia. Revista Ibero Americana de Ciências Ambientais, v.12, n.2, p.715-724, 2021. DOI: http://doi.org/10.6008/CBPC21796858.2021.002.0059 


\section{INTRODUÇÃO}

Quando o termo economia é evocado a ideia imediata é que se reporta a redução de gastos ou pensase em variados índices que são mostrados nos telejornais. Isto não acontece quando o termo ecologia é pronunciado. Não obstante, os dois vocábulos têm o mesmo radical que vem do grego oikos que significa "casa". Em seus sentidos etimológicos o termo economia designa "administração da casa" e o termo ecologia se refere a "estudo da casa". Entretanto, "casa" no sentido usado em economia vai se restringir aos aspectos humanos do ambiente, que envolvem a organização social e o modo como usamos os recursos. Já no sentido da ecologia, "casa" é entendido em um sentido mais amplo que envolve os aspectos da vida dos seres vivos em sua relação com os outros seres e com os elementos não-vivos que os sustentam.

Alcançar um melhor entendimento entre estas diferentes abordagens e áreas do conhecimento os quais a gestão dos recursos naturais ou ambientais suscita, requer um conhecimento aprofundado das razões que explicam a dinâmica da sociedade contemporânea. E sabendo como surgem outras disciplinas que procuravam dar respostas úteis para a gestão ambiental a economia que havia abandonado esta investigação volta a consolidar sua reflexão. O propósito declarado de conectar a reflexão desde diferentes pontos de vista e áreas do conhecimento é fruto de um duplo e óbvio reconhecimento de que a economia não explica de per si todo o problema elencado nesta discussão. Por um lado, é necessário reconhecer que é difícil enfrentar seriamente os problemas ecológicos ou ambientais em que a gestão quotidiana suscita, sem ter um conhecimento físico e territorial preciso deles. Além de admitir que, por mais que se conheça seu aspecto físico e territorial, seria ingênuo pensar em resolvê-los sem levar em conta o quadro institucional e os mecanismos de avaliação que os originam.

A valoração econômica de bens e serviços ambientais é fruto deste entendimento integrado e apresenta-se como uma alternativa para contribuir nos esforços de conservação ambiental. Este mecanismo está inserido em uma interface que envolve o sistema natural e o econômico e com isso o seu uso tem se ampliado em todo o mundo. A percepção de que o ecossistema equilibrado fornece benefícios para a sociedade é um pressuposto básico desta atividade. O conceito de serviço ecossistêmico é um fruto deste entendimento mais sistêmico e integrado da realidade do ambiente. Atribuir valor as coisas é uma atividade que os seres humanos sempre realizaram em sua história e se torna imprescindível para a conservação dos recursos naturais muito devido as transformações tecnológicas ocorridas nos últimos séculos que aumentaram a sua exploração enormemente.

Desta feita, um dos biomas que mais aparece em evidência pelos problemas com a degradação ambiental no cenário mundial é a Amazônia, principalmente devido ao seu potencial de estoque de carbono e da biodiversidade contidos nele. $\mathrm{O}$ desmatamento para o aumento da fronteira agropecuária é apontado como o motivo mais forte para a perda dos serviços ambientais na Amazônia. Os benefícios que o ecossistema amazônico gera aos seres humanos frequentemente não são levados em consideração pelos agentes econômicos que tomam as decisões sobre o uso e ocupação do solo naquela região. Não levando em consideração com isso os custos que as perdas dos serviços ecossistêmicos causam. A diminuição do 
bem-estar da população se dar então como consequência deste processo (CASTRO et al., 2016).

Nesta perspectiva, o artigo em questão busca apreender os custos econômicos provenientes da perda de capacidade da floresta amazônica em oferecer os serviços ecossistêmicos necessários para manutenção da vida no planeta, causados pelo processo de desflorestamento no ano de 2018. O estudo destes custos é realizado nas unidades de conservação encontradas na Amazônia brasileira, que como sendo áreas legalmente instituídas pelo poder público deveriam ser modelos de conservação para todo o resto do território amazônico. A análise feita não se detém nas investigações sobre as causas do desmatamento nestas localidades, mas sim no quanto a sociedade perde em não se manter a fiscalização adequada nessas áreas. Com isso, utilizou-se para a metodologia da estimativa dos custos a técnica de transferência de benefícios.

\section{REVISÃO TEÓRICA}

O agente econômico denomina-se por assim dizer como aquele que almeja ou deseja interferir ou reformular o andamento das coisas ou atividades. Aquele que escolhe, determina e chega a um fim escolhido. Entre duas coisas, escolhe uma e rejeita a outra, não pode ter as duas. De forma que, a ação humana significa então, de alguma forma tanto obter como renunciar (VON MISES, 2017). Sendo assim, a dinâmica do processo de escolha da vida particular, em que temos que levar em conta um trade-off constante, é também válida nas decisões tomadas na sociedade como um todo. Sendo que nas últimas décadas a balança deste trade-off não tem favorecido até o presente momento os recursos ambientais e do consequente equilíbrio ecossistêmico.

Escolhe-se algo normalmente por interesses individuais e nem sempre essas escolhas passam por uma avaliação criteriosa das consequências, no qual leve em consideração aspectos relacionados ao meio ambiente. Isto, por sua vez, não tem nos levado a uma situação favorável no planeta. Entretanto, se considerarmos que ações humanas levaram o planeta a esse estado de crise, também poderá levá-lo a uma situação mais favorável, ou poderíamos dizer, em sintonia com os sistemas ambientais que nos circulam e nos sustentam. Para Von Mises (2017) essa realidade é possível, segundo o autor: " a ação humana é um dos instrumentos que promovem mudança. É um elemento de atividade e transformação cósmica".

Nesta perspectiva, a mudança comportamental envolvendo os agentes transformadores da realidade aparece como algo urgente. O surgimento da escola econômica denominada economia ecológica talvez seja um fruto desta mudança, os defensores dessa linha de pensamento defendem que o sistema econômico não pode mais crescer se quisermos que o planeta recupere seu estado de equilíbrio. Para Daly et al. (2004), o crescimento econômico tem um custo para o planeta, não se cresce para um vazio e sim para um planeta que dar suporte a nossa vida e que é finito. Segundo Georgescu-Roegen (2012), a história dos homens mostra de forma incontestável que o meio ambiente tem uma relação importante no processo econômico e na formação do valor econômico.

Além da economia ecológica a escola econômica neoclássica também aprofundou seus estudos na questão ambiental, o que originou a chamada economia ambiental. Dentro desse escopo teórico, a degradação ambiental é vista como uma externalidade do sistema econômico, no qual impede uma alocação 
eficiente dos recursos na sociedade. Com isso, a principal solução no qual defende essa abordagem é a internalização dessas externalidades no sistema de preços de mercado. Ou seja, a utilização de mecanismos de controle por parte do poder público, como multas ou taxações, que visem a introdução dos custos sociais e ambientais nos preços de bens e serviços econômicos. Outra abordagem da economia ambiental, a economia dos recursos naturais, trata os recursos como fornecedores de matérias-primas para o sistema econômico e foca no estabelecimento do equilíbrio intertemporal atingindo por meio da alocação ótima dos recursos se baseando na tese de Hotelling (QUEIROZ et al., 2012).

Uma questão que tem sido debatida tanto por economistas ambientais como por ecológicos é sobre o valor do meio ambiente. O conceito de valor já era discutido a séculos nas ciências econômicas. Autores clássicos como Adam Smith consideravam o valor como sendo constituído de dois sentidos, o primeiro dizia respeito a utilidade contida nos objetos e o outro com relação ao poder de compra dos mesmos em relação a outra mercadoria. Já para David Ricardo, o valor é originado da escassez e da quantidade de trabalho necessária para obter a mercadoria. Outro autor conhecido, Alfred Marshall, vai ter uma visão diferente dos autores clássicos. Para ele o valor tem relação com a satisfação do consumo de uma mercadoria. Assim, o valor seria medido a partir do conceito de utilidade, que diz respeito ao quanto uma pessoa sente prazer com aquela mercadoria (MOTA et al., 2013).

A economia ambiental se apropria deste último conceito apresentado, tendo em vista que suas bases estão no individualismo metodológico, utilitarismo e equilíbrio. Para essa concepção o bem-estar é visto como uma categoria não-econômica que reflete o conjunto de todas as categorias não-econômicas dos valores sociais (AMAZONAS, 2009). Para Field et al. (2014) " a criação de valor gerada pelas ações econômicas baseia-se na noção fundamental de que os indivíduos têm preferências por bens e serviços. " Os autores consideram que o valor de uma mercadoria para uma pessoa está relacionado com o quanto ela está disposta a sacrificar para consegui-la. Ou seja, sua disposição a pagar por um determinado bem.

Entretanto, segundo Amazonas (2009), esta visão da economia ambiental não é compatível com o Desenvolvimento Sustentável. Pois, segundo o autor a realidade sistêmica complexa, incerta e de dinâmica evolutiva do Desenvolvimento Sustentável "transcende a esfera de percepção, conhecimento, julgamento compensatório, formação de opções e motivação dos indivíduos, sendo, portanto, não traduzíveis por meio das preferências destes". Para ele o uso ótimo dos recursos, objetivo da economia ambiental, não corresponde necessariamente ao uso sustentável dos mesmos. Pois, ele defende que a eficiência é incompatível com a equidade, que é um dos fundamentos do Desenvolvimento Sustentável.

Por outro lado, em uma perspectiva prática é perceptível que a implementação de uma política ambiental as vezes tende a aumentar consideravelmente os gastos públicos e consequentemente os impostos. Com isso, principalmente em países em desenvolvimento, as prioridades das decisões políticas se voltam a outras questões que em determinado contexto de crise interessam normalmente a maior parcela da população. Sendo assim, a atividade de valoração ambiental pode ajudar na captação destas prioridades. Segundo Frör (2007), em uma Sociedade Democrática o governo precisa alocar os fundos públicos de forma a melhor atender as necessidades de bem-estar da população. Neste caso, é sempre importante considerar 
os benefícios para toda a população de qualquer projeto ambiental a ser realizado. Com isso, para o autor a análise de Custo-Benefício pode ser usada como um instrumento de avaliação para tais projetos.

Todavia, nem sempre os benefícios da proteção ambiental são conhecidos pela sociedade. Este conhecimento ficou mais evidente através do trabalho pioneiro de Costanza et al. (1997) que mostrou no artigo The value of the world's ecosystem services and natural capital que os bens (alimentos por exemplo) e serviços (como a assimilação de resíduos) são benefícios que a sociedade obtém por meio das funções ecossistêmicas. Desde então, o estudo sobre os serviços ambientais ou serviços ecossistêmicos se popularizou e vem ganhando enorme atenção nos projetos de preservação ambiental (PARRON et al., 2015). Os principais serviços ambientais são apresentados na Tabela 1.

Tabela 1: Classificação dos serviços ambientais em serviços de provisão, regulação, culturais e de suporte.

\begin{tabular}{|c|c|}
\hline Categorias & Exemplos de serviços \\
\hline Serviços de suporte & $\begin{array}{l}\text { Manutenção } \text { da } \\
\text { Manutenção do ciclo de vida (ciclagem de nutrientes e da } \\
\text { água/fotossíntese) } \\
\text { Formação do solo }\end{array}$ \\
\hline Serviços de provisão & $\begin{array}{lr}\text { Alimentos } & \\
\text { Fibras/madeira } & \\
\text { Recursos } & \text { genéticos } \\
\text { Recursos } & \text { medicinais } \\
\text { Recursos } & \text { ornamentais } \\
\text { Água potável } & \end{array}$ \\
\hline Serviços de regulação & 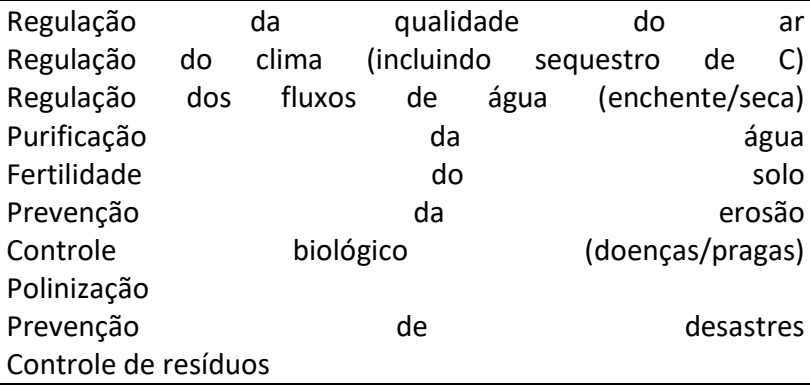 \\
\hline Serviços culturais & \begin{tabular}{lccr} 
Valores & \multicolumn{2}{c}{ estéticos } & (paisagem) \\
Recreação & e & & turismo \\
Valores & espirituais & e & religiosos \\
Valores educacionais/culturais & &
\end{tabular} \\
\hline
\end{tabular}

Fonte: MEA (2005).

Segundo Andrade (2013), os serviços ecossistêmicos ou ambientais são compreendidos como o campo de interação entre os ecossistemas e o bem-estar humano, sem os quais não tem possibilidade de existir vida no planeta. Com isso, pelo grau de importância que os ecossistemas têm para a vida na terra, se faz necessário o conhecimento dos seus valores verdadeiros para dessa forma aplicar políticas públicas mais ecologicamente eficientes de conservação das florestas (ANDRADE, 2013). Sendo assim, os valores atribuídos aos serviços ambientais são classificados como valor de uso e valor de não-uso (VNU) ou valor de existência. Para Motta (1997), o valor de uso pode ainda ser subdividido em valor de uso direto (VUD), valor de uso indireto (VUI) e valor de opção (VO) (valor de uso potencial). Com isso, o valor econômico de um recurso ambiental (VERA) pode ser escrito como na equação (1):

$$
\mathrm{VERA}=(\mathrm{VUD}+\mathrm{VUI}+\mathrm{VO})+\mathrm{VNU}(1)
$$

A mensuração destes termos da equação é feita através de sofisticados métodos desenvolvidos no campo de estudo da economia ambiental. Estes métodos estão divididos em métodos da função de produção 
e métodos da função de demanda. Os métodos da função de produção (produção sacrificada ou custos evitados) consideram o recurso natural como um insumo da produção e a partir da variação destes insumos a mensuração dos recursos é feita. Segundo Motta (2006) " se o impacto altera a quantidade produzida do bem privado, o valor econômico desse impacto pode ser mensurado pela variação de receita líquida desta alteração de produção. " Já com relação aos métodos da função de demanda (preços hedônicos, custo de viagem e valoração contingente), a mensuração do valor ambiental é feita através das preferências individuais. A variação do excedente do consumidor é medida em função de uma variação da disponibilidade dos recursos (MOTTA, 2006). Estes métodos consideram os benefícios como a quantia que as pessoas estariam dispostas a pagar por um determinado serviço ambiental (FIELD et al., 2013).

\section{METODOLOGIA}

A técnica de transferência de benefícios é um método estimativo de benefícios dos serviços ecossistêmicos de uma localidade para a mensuração em outro local específico. A localidade em que as estimativas são realizadas é denominado local de estudo tendo este local recebido uma avaliação inicial. No outro lado se tem a localidade em que a técnica é empregada e é denominada de local para aplicação de política, devido que a transferência de benefícios é parte integrante de uma análise econômica que tem como seu objetivo final a construção de uma política governamental (PLUMMER, 2009). A aplicação desta técnica tem algumas limitações e uma delas é o fato de depender que se tenha um estudo em lugares semelhantes ao local de aplicação. Por causa disso, se faz necessário existir uma correspondência entre o local de estudo e o local para aplicação da política. Essa correspondência pode ser alguma semelhança de natureza ambiental, biofísica, social ou econômica de forma que isto vai melhorar a precisão do método (CASTRO et al., 2016).

Os dados estimados na pesquisa em questão para servir como correspondência para o local do objeto de estudo foram retirados do trabalho intitulado Global estimates of the value of ecosystems and their servicesin monetary units, dos autores de Groot et al. (2012). Este trabalho oferece uma visão geral do valor dos serviços ecossistêmicos de 10 biomas principais expressos em unidades monetárias. No total, mais de 320 publicações foram investigadas abrangendo mais de 300 locais de estudo de caso. Com isso, foram estimados aproximadamente 1350 valores sendo armazenados no banco de dados Ecosystem Service Value Database (ESVD). Uma seleção de 665 estimativas de valores foi utilizada para a análise. 0 estudo mostra que o valor total dos serviços ambientais é relevante e varia entre $4902007 \$ /$ ha/ano para os serviços ecossistêmicos oferecidos pelos oceanos a quase 350.000 2007\$/ha/ano para os serviços de recifes de coral. No estudo em questão, foi usado os valores médios encontrados para o bioma floresta tropical.

Para calcular o valor dos serviços ecossistêmicos perdidos (VSE) em função das unidades de conservação da região amazônica brasileira, o primeiro passo foi separar as estimativas econômicas do bioma floresta tropical presentes em de Groot et al. (2012) e convertê-las para a moeda brasileira (real), conforme mostra a Tabela 1. A transformação foi feita de acordo com os índices de inflação da economia norte- 
americana entre os anos 2007 e $2018^{1}$. Posteriormente, a conversão foi feita para o real (R\$) com base na taxa de câmbio média de 2018 - US\$ 1 = R\$3,65 - disponibilizada pelo Banco Central. No passo seguinte, foi calculado o VSE em função do desmatamento nas unidades de conservação da Amazônia usando a equação (2) (CASTRO et al., 2016).

$$
V S E_{i, j}=\alpha_{i} x \text { área }_{j} \text { (2) }
$$

Em que:

$V S E_{i, j}=$ Valor do serviço ecossistêmico perdido i no ano j; $\alpha_{i}=$ Cifra monetária do serviço ecossistêmico i; área $_{j}=$ Área desmatada em hectare no ano j.

Por fim, se calculou o valor agregado dos serviços ecossistêmicos mensurados pela equação anterior para o ano de 2018, encontrando então o custo econômico do desmatamento (CED) com a equação (3).

$$
C E D=\sum V S E_{i j}(3)
$$

\section{RESULTADOS E DISCUSSÃO}

As unidades de conservação do bioma Amazônia que apresentaram casos de desmatamento registrados no ano de 2018 segundo o ICMbio são das categorias: Área de Proteção Ambiental (APA), Área de Proteção Integral (ARIE), Estação Ecológica (ESEC), Reserva Biológica (REBIO), Parque Nacional (PARNA), Reserva Extrativista (RESEX) e Floresta Nacional (FLONA). Dentro destas, os casos registrados de desmatamento mais frequentes foram encontrados nas categorias de unidade de conservação Reserva Extrativista e Floresta Nacional, como mostra a Figura 1.

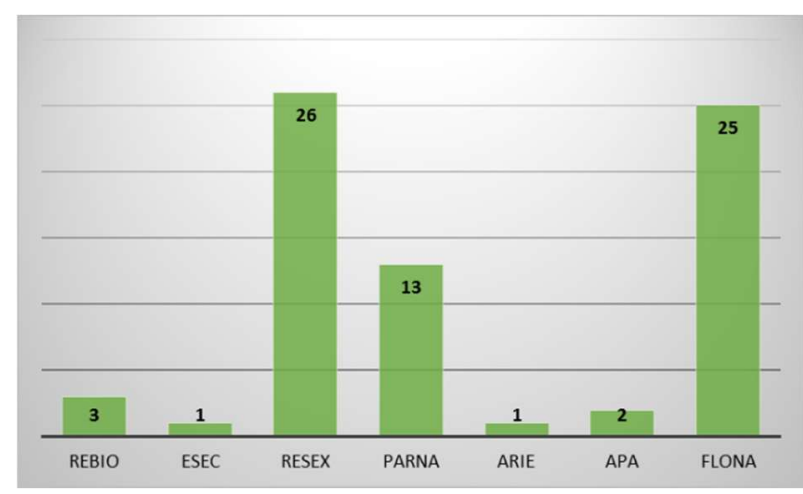

Figura 1: Quantidade de casos registrados de desmatamento nas diferentes categorias de unidade de conservação no bioma Amazônia.

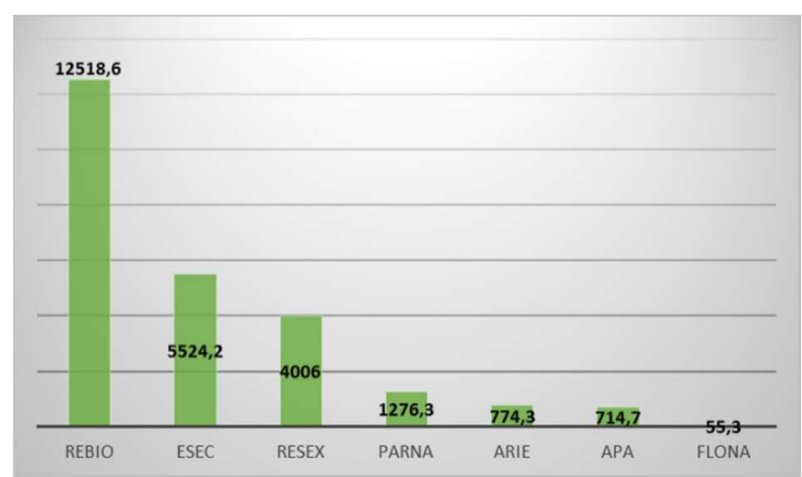

Figura 2: Área desmatada em hectare nas diferentes categorias de unidade de conservação no bioma Amazônia.

Fonte: ICMbio (2018).

Com relação a área de desmatamento total no ano de 2018, a categoria que mais foi afetada foi a Reserva Biológica. Registrando no ano em questão uma área total de 12.518,6 ha, representando com isso mais de 50\% de toda área desmatada no bioma Amazônia entre as unidades de conservação, seguida pelas categorias Estação Ecológica e Reserva Extrativista com 5524,2 ha e 4006,0 ha respectivamente. A Figura 2 mostra a área total de desmatamento por categoria de unidade de conservação.

A área total desmatada nestas unidades de conservação foi usada para o cálculo de valoração dos 
serviços ecossistêmicos em estudo. Os serviços escolhidos para tal mensuração e os valores escolhidos como base foram tirados do trabalho dos autores de Groot et al. (2012). Os serviços consistem em serviços de fornecimento, de regulação, de habitat e culturais. O valor de cada serviço em específico é mostrado na Tabela 2, assim como a soma de cada tipo. O valor total encontrado em $\mathrm{R} \$ 2018 /$ ha/ano para os serviços ecossistêmicos do bioma Amazônia foi R\$23.407,77 2018/ha/ano.

Tabela 2: Valor econômico dos serviços ecossistêmicos em US\$2007/ha/ano, US\$2018/ha/ano e R\$2018/ha/ano.

\begin{tabular}{|c|c|c|c|}
\hline SERVIÇOS & VALORES (US\$2007/ha/ano) & VALORES (US\$2018/ha/ano) & VALORES (R\$2018/ha/ano) \\
\hline SERVIÇOS DE FORNECIMENTO & 1828 & 2183 & $\mathrm{R} \$ \mathrm{~T}_{7.969,29}$ \\
\hline Alimentos & 200 & 239 & 872 \\
\hline Abastecimento de água (doce) & 27 & 32 & 118 \\
\hline Matérias-primas & 84 & 100 & 366 \\
\hline Recursos genéticos & 13 & 16 & 57 \\
\hline Recursos medicinais & 1504 & 1796 & 6557 \\
\hline SERVIÇOS DE REG ULAÇÃO & 2529 & 3114 & RȘ 11.366,49 \\
\hline Influência na qualidade do ar & 12 & 15 & 54 \\
\hline Regulação climática & 2044 & 2517 & 9187 \\
\hline Moderação de eventos extremos & 66 & 81 & 297 \\
\hline Re gulação dos fluxos de água & 342 & 421 & 1537 \\
\hline Tratamento de resíduos/purificação de água & 6 & 7 & 27 \\
\hline Prevenção da erosão & 15 & 18 & 67 \\
\hline Ciclagem dos nutrie ntes e manute nção da fertilidade do solo & 3 & 4 & 13 \\
\hline Polinização & 30 & 37 & 135 \\
\hline Controle Biológico & 11 & 14 & 49 \\
\hline SERVIÇOS DE HABITAT & 39 & 48 & RȘ 175,28 \\
\hline Manute nção do ciclo de vida & 16 & 20 & 72 \\
\hline Diversidade Genética & 23 & 28 & 103 \\
\hline SERVIÇOS CULTURAIS & 867 & 1068 & $\mathrm{R} \$ 3.896,70$ \\
\hline Oportunidades de recreacão e turismo & 867 & 1068 & 3897 \\
\hline
\end{tabular}

Fonte: Groot et al. (2012).

Com isso, os VSE (Valor do Serviço Ecossistêmico) das áreas desmatadas no ano de 2018 foram encontrados para cada categoria de unidade de conservação usando a Equação 1. O resultado encontra-se na Figura 3. Então, a partir disto foi encontrado o CDE (Custo Econômico de Desmatamento) para o ano de 2018 nas unidades de conservação da Amazônia somando os valores do VSE. O CDE encontrado foi de R\$ 582.137.181,06, o que representou 0,01\% do PIB brasileiro naquele ano.

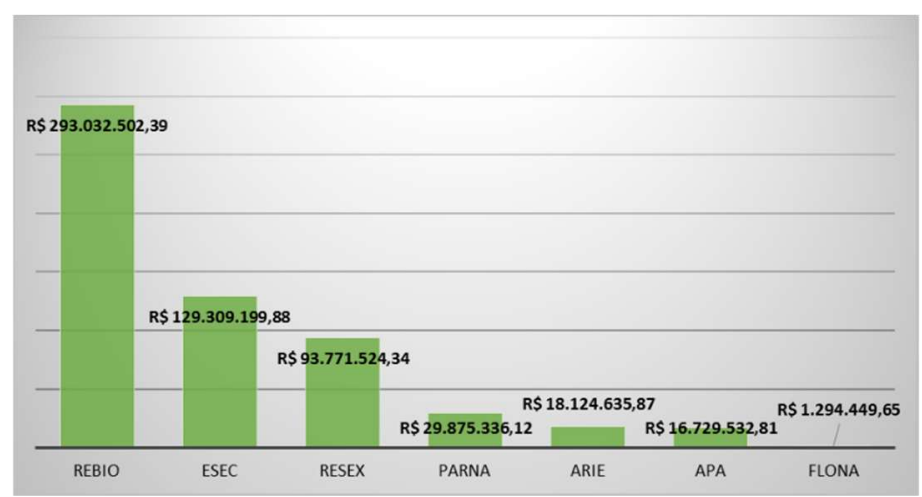

Figura 3: VSE para cada categoria de unidade de conservação.

Segundo a Lei 9985/00 que institui o Sistema Nacional de Unidades de Conservação da Natureza (SNUC) a Reserva Biológica é uma categoria incluída no grupo de Unidades de Proteção Integral. Diferentemente de uma Unidade de Uso Sustentável, que permite um compartilhamento entre o uso dos recursos e a preservação, as Unidades de Proteção Integral só permitem o uso indireto dos recursos naturais em seu interior. E ainda mais a categoria Reserva Biológica apresenta restrições bem claras com relação ao 
nível de preservação em sua área no Art.10 da referida lei "[...] sem interferência humana direta ou modificações ambientais[...]". Com isso, é perceptível que a realidade ambiental das Reservas Biológicas da Amazônia vem sofrendo com ações antrópicas que ocorrem de forma irregular. Além do mais, isto vem fazendo com que a sociedade perca benefícios provenientes dos serviços oferecidos por meio dos ecossistemas dessas áreas.

Por fim, é notório a urgência de um aumento na fiscalização dessas áreas legalmente instituídas pelo poder público. Tendo em vista tanto a importância para o bem-estar da população local na região como a relevância em nível global que o bioma Amazônia tem no cenário atual. Nesse sentido, a atividade de valoração é imprescindível para que aumente a visibilidade da relevância para a vida humana da preservação dos ecossistemas naturais. Tanto como forma de conscientização da população como principalmente dos tomadores de decisões tanto públicos como privados.

\section{CONCLUSÕES}

O desmatamento sendo um resultado de uma escolha humana, seja ela tomada de forma individual ou coletiva, é sempre pautado em obter o máximo benefício possível para o indivíduo ou grupo. No entanto, o benefício que se apresenta para alguns pode ser perdido para tantos outros. E estas perdas nem sempre são claras e conscientes para os atores envolvidos no processo. Assim como, a preservação de um ambiente por si só tem um valor próprio que independe da existência de uma variação do bem-estar humano ou não, no qual é chamado tecnicamente de valor de existência. A dinâmica envolvida nesta interface entre a estrutura social e a estrutura ambiental foi um norte que este artigo tentou abarcar.

O fenômeno escolhido para refletir está dinâmico foi o valor perdido pelo desflorestamento em

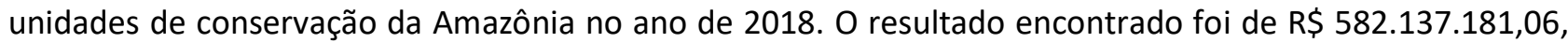
representando $0,01 \%$ do PIB do referido ano. Dentre esta cifra, a maior perda foi encontrada nas Reservas Biológicas, refletindo quase $50 \%$ do total das perdas. A categoria de unidade de conservação Reserva Biológica por lei teria que ter um regime de uso dos seus recursos sem nenhuma interferência humana, diferentemente de outras categorias como as do grupo de uso sustentável (APA, ARIE, FLONA e RESEX). Porém, está restrição definida por lei (Lei 9985/00) se mostrou falha de acordo com os dados tirados do ICMbio.

Logo, a atividade de valoração dos serviços ambientais mostra-se importante neste processo que envolve decisões críticas envolvendo o ambiente natural. Pois, de um lado existe a necessidade de alertar os gestores públicos para a possibilidade de uma perda irreversível para o planeta e de outro a conscientização dos agentes transformadores sobre os possíveis rendimentos negativos que poderão sofrer. Assim como, essas decisões tomadas poderão atender de forma efetiva a maior parcela da população que muitas vezes sentem o impacto da degradação do ambiente, mas estão dependentes destas decisões. Neste caso, o artigo pretendeu tanto contribuir nas aplicações de metodologias adequadas para essa atividade quanto promover o incentivo a futuros trabalhos dirigidos para o estado encontrado nas unidades de conservação no Brasil. 


\section{REFERÊNCIAS}

AMAZONAS, M. C.. Valor ambiental em uma perspectiva heterodoxa institucional-ecológica. Economia e Sociedade, v.18, n.1, p.183-212, 2009.

ANDRADE, D. C.. Valoração econômico-ecológica: bases conceituais e metodológicas. São Paulo: Annablume, 2013.

BRASIL. Lei n. 9.985 de 18 de julho de 2000. Institui o Sistema Nacional de Unidades de Conservação - SNUC. Brasília: DOU, 2000.

CASTRO, A. S.; ANDRADE, D. C.. O custo econômico do desmatamento da Floresta Amazônica brasileira (19882014). Perspectiva Econômica, v.12, n.1, p.1-15, 2016. DOI: http://dx.doi.org/10.4013/pe.2016.121.01

COSTANZA, R.; D'ARGE, R.; GROOT, R.; FARBER, S.; GRASSO, M.; HANNON, B.; LIMBURG, K.; NAEEM, S.; O'NEILL, R. V.; PARUELO, J.; RASKIN, R. G.; SUTTON, P.; VAN DEN BELT, M.. The value of the world's ecosystem services and natural capital. Nature, v.387, n.6630, p.253-260, 1997. DOI: http://dx.doi.org/10.1038/387253a0

DALY, H.; FARLEY, J.. Economia Ecológica: princípios e aplicações. Lisboa: Instituto Piaget, 2004.

FIELD, B. C.; FIELD, M. K.. Introdução à economia do meio ambiente. 6 ed. Porto Alegre: AMGH LTDA., 2014.

FRÖR, O.. Rationality concepts in environmental valuation. Berlin: Peter Lang International Academic Publishers, 2007.

GEORGESCU-ROEGEN, N.. O decrescimento. Entropia: Ecologia: Economia. São Paulo: Senac, 2012.

GROOT, R.; BRANDER, L.; VAN DER PLOEG, S.; COSTANZA, R.; BERNARD, F.; BRAAT, L.; CHRISTIE, M.; CROSSMAN, N.; GHERMANDI, A.; HEIN, L.; HUSSAIN, S.; KUMAR, P.;
MCVITTIE, A.; PORTELA, R.; RODRIGUEZ, L. C.; TEN BRINK, P.; VAN BEUKERING, P. V.. Global estimates of the value of ecosystems and their services in monetary units. Ecosystem Services, v.1, p.50-61, 2012. DOI:

http://dx.doi.org/10.1016/i.ecoser.2012.07.005

MEA. Millennium Ecosystem Assessment. Ecosystem and human well-being: Synthesis. Washington: Island Press, 2005.

MOTA, J. A.; BURSZTYN, M.. O valor da natureza como apoio a decisão pública. Revista paranaense de desenvolvimento, Curitiba, v.34, n.125, p.39-56, 2013.

MOTTA, R. S.. Economia ambiental. Rio de Janeiro: FGV, 2006.

MOTTA, R. S.. Manual para valoração econômica de recursos ambientais. Rio de Janeiro: IPEA, 1997.

PARRON, L. M.; GARCIA, J. R.. Serviços ambientais: conceitos, classificação, indicadores e aspectos correlatos. In: PARRON, L. M.; GARCIA, J. R.; OLIVEIRA, E. B.; BROWN, G. G.; PRADO, $R$. B.. Serviços ambientais em sistemas agrícolas e florestais do Bioma Mata Atlântica. Embrapa Florestas, 2015.

PLUMMER, M. L.. Assessing benefit transfer for the valuation of ecosystem services. Frontiers in Ecology and the Environment, v.7, n.1, p.38-45, 2009.

QUEIROZ, C. N.; BORTOLUZI, C. R. D.. Os economistas, o meio ambiente e a gestão dos recursos naturais: em busca do diálogo entre distintas abordagens. In: BARBOSA, E. M.; BATISTA, R. C.; BARBOSA, M. F. N.. Gestão dos recursos naturais: uma visão multidisciplinar. Rio de Janeiro: Ciência Moderna Ltda., 2012.

VON MISES, L.. A ação humana. LVM, 2017.

A CBPC - Companhia Brasileira de Produção Científica (CNPJ: 11.221.422/0001-03) detém os direitos materiais desta publicação. Os direitos referem-se à publicação do trabalho em qualquer parte do mundo, incluindo os direitos às renovações, expansões e disseminações da contribuição, bem como outros direitos subsidiários. Todos os trabalhos publicados eletronicamente poderão posteriormente ser publicados em coletâneas impressas sob coordenação da Sustenere Publishing, da Companhia Brasileira de Produção Científica e seus parceiros autorizados. Os (as) autores (as) preservam os direitos autorais, mas não têm permissão para a publicação da contribuição em outro meio, impresso ou digital, em português ou em tradução. 